\title{
Impact of Individual and Urban Traits and Urban Form on Vehicle Hours Traveled
}

\author{
Gunwon Lee ${ }^{1}$, Yunnam Jeong ${ }^{2}$ and Seiyong Kim*³ \\ ${ }^{1}$ Assistant Professor, Division of Architecture, Mokwon University, Korea \\ ${ }^{2}$ Visiting Professor, Department of Architecture, Built Environment and Construction Engineering, Politecnico di Milano, Italy \\ ${ }^{3}$ Professor, Department of Architecture, Korea University, Korea
}

\begin{abstract}
This study is aimed at investigating correlations regarding the impacts of individual traits, urban character, and urban form on Vehicle Hours Traveled (VHT). It takes the approach of focusing on the 5Ds, major elements of urban character and urban form that influence VHT. The 5Ds encompass the widely-known factors for reducing VHT through the 3Ds (density, diversity, design) introduced by Cervero and Kockelman (1997), as well as two additional elements of distance to transit and destination accessibility as appended by Ewing et al. (2008). This study utilizes individual traits, transportation data on individuals, and statistical data on cities provided by each city within micro data at the $2 \%$ level from the Micro Data Service System (MDSS) of the 2005 Population and Housing Census Data. It applies the Hierarchical Linear Model (HLM) to analyze 79 cities with a population between 0.1 and 3 million and their residents, taking into account both the individual and urban levels. The 5Ds demonstrate a significant relation to the reduction of VHT. However, we conclude that density, a conventional element for enabling a reduction in VHT in Western cities, does not have a similarly great impact within the context of Korean cities. This research result is significant in that it provides basic data for the establishment of policies regarding the reduction of commuting time by car.
\end{abstract}

Keywords: compact city; VHT (Vehicle Hours Traveled); 5Ds (density, diversity, design, destination accessibility, distance to transit); HLM (Hierarchical Linear Model)

\section{Introduction}

Sustainable urban development, low-energy cities and low-carbon cities have all been the subject of considerable worldwide attention in relation to the increasing threat of calamities and economic losses caused by climate change. In particular, atmospheric carbon is a well-known factor in raising the earth's temperature through the greenhouse effect and thus fostering dramatic climate change. Consequently, reducing carbon emissions has emerged as one of the topics in the discussion of environmentally friendly and sustainable cities (Tumlin, 2011).

Notably, it has been found that $10 \%$ to $30 \%$ of the carbon emitted in cities is produced by the transportation sector (EPA, 2013). Automobile use by individuals is a known major culprit among such carbon emissions. In response, a great deal of research (Zhou \& Kockelman, 2008; Bhat \& Eluru, 2009) has been conducted on methods to reduce individual

*Contact Author: Seiyong Kim, Professor,

Department of Architecture, \#314, Engineering Building, Korea University, Anam-dong, Sungbuk-gu, Seoul, 136-713, Korea

Tel: +82-2-3290-3914 Fax: +82-2-921-7947

E-mail:kksy@korea.ac.kr

(Received October 8, 2014 ; accepted June 25, 2015 ) vehicle use.

Meanwhile, scholars have pointed out that when focusing on vehicle use by individuals, urban-level elements such as urban form and character influence individual car use (Newman \& Kenworthy, 1989). Since this pioneering research, a key to urban studies regarding the reduction of car use has become the question of in which cities do residents use cars more often or less frequently.

This study aims to approach VHT in three aspects: the individual level, urban character, and urban form, and then reveal the relation between VHT and these three elements. In particular, by focusing on the 5Ds, composed of the 3Ds introduced by Cervero \& Kockelman (1997) plus distance to transit and destination accessibility as appended by Ewing et al. (2008), which are all considered major factors for the reduction of VHT, it attempts to perform an analysis of their relation with VHT.

\section{Literature Review \& Hypothesis \\ 2.1 Literature Review}

As described by Ewing \& Cervero (2010), vehicle use shows a similar mechanism in terms of both VMT (Vehicle Miles Traveled) and VHT. VMT, which was the subject of previous research, is a consumption index of vehicle energy in major cities. However, 
it does not reflect declines in vehicle speed due to congestion within a city and the resultant increase in VHT. This is why Ewing et al. (1996) instead examined VHT. This study applies VHT for the same reason.

Most research in this area focuses on which urban forms and characters might reduce car use and VHT. Such research is interested in whether compact cities are in fact capable of minimizing vehicle use and VHT. The 5Ds are addressed in this same context. However, there are various contentions surrounding whether compact city-related factors do in fact actually decrease car use and VHT. Research on these arguments can be divided between two camps: supporters of compact cities and those casting doubt on the related research results.

First, research has been reported which supports urban planning focusing on high density and complexity by concluding that such density and complicated land uses result in less car traffic. One of the most advanced studies in this regard is that by Newman \& Kenworthy (1989), which concludes on the basis of an investigation of gasoline consumption and density in 32 cities worldwide that land use characterized by high density is indeed efficient in decreasing energy consumption. Cervero \& Kockelman (1997) classify urban character and methods through the 3Ds, and conclude that these systems can be highly effective in decreasing the choice to use a car.

Second, research has been published that does not aggressively oppose development with high density and complexity, but does raise related questions. Breheny (1996) points out that the compressed city model shows difficulties in propelling policies due to urban sprawl and the preference for living along a city's outskirts. The multi-faceted verifications of the correlation between transportation and energy consumption in the compressed urban space are insufficient, suggesting a need for additional research. According to a study by Banister (1992) on the United Kingdom, transportation energy consumption marks its highest level in small cities located farthest from a central city.

\subsection{Research Questions}

Similar to those set out in papers that raise questions regarding the compact city, five hypotheses are described below that identify the compact city and sustainable urban design. First, as indicated by Handy et al. (2005), every region or city features factors that reduce car traffic. That is, there may be possibilities for different cities to demonstrate unique car choice patterns. Second, the bulk of existing studies that analyzed the relationship between the 5Ds and car preferences did not undertake the exclusion of various factors which may be important in affecting car decisions, as indicated by Ewing and Cervero (2001) and Handy et al. (2005). Therefore, when individual factors are excluded from such studies, their conclusions may diverge from those preceding them. Third, similar to the conclusions for cities in Europe (De Bourdeaudhuij et al., 2003), Korean cities that are already particularly dense and complex show a considerable potential to reveal divergent tendencies on the correlation between the 5Ds and car traffic volume.

\subsection{Hypothesis}

The hypotheses to be proposed in this study on the basis of the questions above are as follows:

1. VHT differ among cities.

2. Individual variations including age, gender, and income would affect VHT.

3. As has been established, urban form may influence a reduction of VHT.

4. South Korean cities with high density and complexity would have a more significant relation with the other three elements than with density and diversity.

5. The degree of impact that variables at the individual level have on VHT may vary according to the city.

\section{Analysis Structure \\ 3.1 Analysis Models}

This study applies this model for the simultaneous examination of two different models in individuals and their nested cities in order to verify the hypotheses above. The models used in this study are expressed through the following formula:

$$
\begin{aligned}
& V H T_{i j}=\beta_{0 j}+\sum_{k=1}^{l} \beta_{k j} X_{k i j}+r_{i j}, \quad r_{i j} \sim N\left(0, \sigma^{2}\right) \ldots \\
& \beta_{o j}=\gamma_{00}+\sum_{s=1}^{m} \gamma_{0 s} Y_{s 0 j}+\mu_{0 j}, \quad \mu_{0 j} \sim N\left(0, \tau_{00}\right) \ldots \\
& \beta_{k j}=\gamma_{k 0}+\mu_{k j} \ldots(k)
\end{aligned}
$$

Equation (1) is a model of choice of transportation modes at the individual level. $V H T_{i j}$ is a dependent variable that dummy codes vehicle use time, $X_{k i j}$ is the $k$ th independent variable of the $i$ th person in the city $\mathrm{j}, \beta 0 j$ is the intercept of the city $j, \beta_{k j}$ is the regression coefficient of $X_{k}$ of the city $j$, and $r_{i j}$ is the random error of the $i$ th person in the city $j$. This assumes a distribution with an average of zero and a standard deviation of $\sigma^{2}$. Here, the regression coefficient $\beta k j$ shows how the choice of means of passage by an individual is distributed according to the socioeconomic variables in the city $j$. As stated above, the model, a model with level two having constant terms and level one having a dependent variable, and equation (2) show this idea.

Equation (2) is the urban level of the intercept. $\beta_{o j}$ is the intercept of the city $j ; \gamma_{00}$ is the intercept in the model at the urban level; $Y_{s o j}$ is the variable in the urban character or urban form of the $s$ th city in the city $j ; \gamma_{0 s}$ is the regression coefficient of $Y_{s}$; and $\mu_{o j}$ is the 
random order of the city $j$. It is assumed that $\mu_{o j}$ has an average of zero and a standard deviation of $\tau_{00}$ in the distribution.

Similar to equation (2), equation (k) is an urban level model with the regression coefficient of $\beta_{k j}$ rather than with the intercept, and shows the repetition of $k$ as $\beta_{k j}$ repeats $k$ times. Equation (k) should have the intercept of $\gamma_{k 0}$, the urban level variable of $Y_{s k j}$, and the random error of the city $j$ with $\mu_{k j}$. However, this study did not add the urban level variable of $Y_{s k j}$ since it only acknowledges a difference in average value among cities driven by the introduction of the independent variable and does not consider the fact that there is a difference by city. However, it applies $\mu_{k j}$ for the reason described in the following paragraph.

\subsection{Variables Analyzed}

This study divided the various independent variables between those at the individual and urban levels and then categorized the latter into 5D variables and urban form variables. After verifying the effect of individual character, 5D variables, and urban form variables, it analyzed an integrated model which input and controlled all variables and then verified the effect of each one. This study uses Stata 13.0 and HLM 7.01, with a minimum significance level of $10 \%$.

Eight variables were used at the individual level, including VHT (dependent variable), which consisted of individuals' basic characteristics such as gender, age, educational level, and housing tenure, along with socio-economic status. Definitions of each variable are listed in Table 1. Place of residence was divided between inner city and suburban, depending on whether the subjects were living in or outside the city.

Table 1. Individual-level and Dependent Variables

\begin{tabular}{cc}
\hline Variables & Operational Definition \\
\hline Gender & 0: Male, 1: Female \\
Age & 0: 18, 1: 19 56: 74, 57: 75 years old \\
Education & 0: Elementary school, 1: Middle, 2: High, \\
Background & 3: College, 4: Graduate \\
Job & 0: Others, 1: Professional, 2: Engineering, \\
& 3: Office work, 4: Service work, 5: Sales \\
& work, 6: Agriculture, 7: Technical work, \\
& 8: Machine operation, 9: Labor work \\
Housing & 0: Free housing, 1: Home-ownership, 2: \\
tenure & Lump-sum deposit-based, 3: Monthly \\
rent & 0: Mass transportation, 1: Car \\
Transportation & 0: Inner city, 1: Suburban \\
modes & 0: 1-5 min, ...., 24: 116-120 min \\
\hline
\end{tabular}

This study reviewed the $5 \mathrm{D}$ variables made up of the 3Ds suggested by Cervero \& Kockelman (1997) and distance to transit and destination accessibility of Ewing et al. (2008), as well as additional urban form variables. However, unlike in the above two studies, it examines the regional level and deals with a broader space. Therefore, variables were chosen which use data available at the local level regarding the 5Ds variables as defined in research covering VMT and VHT. A variable utilized by Cervero (2006) and Rajamani et al. (2003) was selected as the definition of density, and a variable used by Bento et al. (2003) was selected as the definition of diversity. As for the definition of design, a variable applied by Cervero \& Kockelman (1997), and Frank et al. (2009) was chosen. Table 2. shows the definition of each variable, including the variables described below.

Table 2. Density, Diversity, Design-related Variables

\begin{tabular}{lc}
\hline Variables & \multicolumn{1}{c}{ Operational Definition } \\
\hline Density & Pop. (person)/Urbanization area $\left(\mathrm{km}^{2}\right)$ \\
Diversity & \multicolumn{1}{c}{$1-\sum_{\mathrm{i}=1}^{\mathrm{N}} \mathrm{p}_{\mathrm{i}}{ }^{2}$} \\
& \multicolumn{1}{c}{$\left(\mathrm{p}_{\mathrm{i}}\right.$ : the proportion of total residential areas } \\
& against residential or business areas in i zone) \\
Design & $\begin{array}{l}\text { No. of local road intersections/Total length of } \\
\text { local roads }(\mathrm{m})\end{array}$ \\
\hline
\end{tabular}

Variables related to the additional two elements of distance to transit and destination accessibility were also drawn from similar research. Studies by Ewing et al. (2009) and Kitamura et al. (1997) were used for distance to transit, while publications by Cervero (2006) and Bento et al. (2003) were selected for destination accessibility. However, accessibility was calculated using Standard Deviation Distance (SDD), with the equation as follows:

$$
S D D=\sqrt{\frac{\sum_{i=1}^{n} p_{i\left(x_{i}-\bar{X}\right)^{2}}}{\sum_{i=1}^{n} p_{i}}+\frac{\sum_{i=1}^{n} p_{i\left(y_{i}-\bar{Y}\right)^{2}}}{\sum_{i=1}^{n} p_{i}}} \cdots
$$

${ }^{*} \mathrm{x}_{\mathrm{i}}, \mathrm{y}_{\mathrm{i}}$ : central point coordinate in each dong, $\mathrm{p}_{\mathrm{i}}$ : pop. of each district

The definitions of variables related to distance to transit and destination accessibility are shown in Tables 3 . and 4 .

Table 3. Variables Related to Distance to Transit

\begin{tabular}{cc}
\hline Variables & Operational Definition \\
\hline Bus accessibility & No. of bus stops/Urbanization area $\left(\mathrm{km}^{2}\right)$ \\
Subway & Station area of influence $\left(\mathrm{km}^{2}\right) /$ \\
accessibility & Urbanization area $\left(\mathrm{km}^{2}\right)$ \\
\hline *Station area of influence: area of a circle with a radius of $0.55 \mathrm{~km}$
\end{tabular}

(within the range of walking) whose center is a subway or train station

Table 4. Variables Related to Destination Accessibility

\begin{tabular}{cc}
\hline Variables & Operational Definition \\
\hline Commercial & Total commercial area within $\mathrm{CBD}\left(\mathrm{km}^{2}\right) /$ \\
& $\mathrm{CBD}$ area $\left(\mathrm{km}^{2}\right)$ \\
Apartment & Total apartment area within $\mathrm{CBD}\left(\mathrm{km}^{2}\right) / \mathrm{CBD}$ \\
& area $\left(\mathrm{km}^{2}\right)$ \\
Business use & Total business area within $\mathrm{CBD}\left(\mathrm{km}^{2}\right) / \mathrm{CBD}$
\end{tabular}
$\operatorname{area}\left(\mathrm{km}^{2}\right)$

*Total commercial/apartment/business area within CBD: area of commercial /apartment/business sites within CBD; Total CBD area: area of CBD by each urban plan

In addition, this study considered compact city or other urban forms that are deemed important 
variables according to research on urban sprawl as factors affecting VHT. Compact cities are known to demonstrate an imbalance toward a particular central area (center of the city), compactness, and clustering distribution (Tsai, 2005). Gini Centrality and Moran coefficient (below Moran's I) as suggested by Tsai (2005) were used as the variables for measuring the compactness of urban form. In particular, Gini Centrality is considered to indicate the particular imbalance of a site in terms of urban form. A higher value for this variable corresponds to a wider imbalance. Relative entropy, suggested by Tsai (2005) as a means to measure the dispersion and compression of cities, was also used to gauge the urban form. A higher figure means a more compact structure. Moran's I, which has been used in various studies (Tsai, 2005; Zhao, 2011), was selected as a variable to analyze whether highly populated areas show clustering distribution or random distribution. A higher value indicates a clustering distribution. Lastly, SDD was added in order to examine the distance between a highly populated area and the geometrical center of the city. A lower figure means a compact city. A basic spatial unit for Gini Centrality, Relative Entropy, and Moran's I was "dong," a minimum administrative unit used in Korea.

Table 5. Variables Related to Urban Form

\begin{tabular}{|c|c|}
\hline Division & Operational Definition \\
\hline $\begin{array}{l}\text { Gini } \\
\text { centrality }\end{array}$ & $\begin{array}{c}\sum_{i=0}^{n-1}\left|x_{i} y_{i+1}-x_{i+1} y_{i}\right| \\
\text { (x: accumulated area ratio of i zone, } \mathrm{y}_{\mathrm{i}} \text { accumulated pop. ratio of area i) }\end{array}$ \\
\hline $\begin{array}{l}\text { (Relative) } \\
\text { entropy }\end{array}$ & $\begin{array}{c}\sum_{i=1}^{N} P D E N_{i} \times \log \left(\frac{1}{P D E N_{i}}\right) / \log (N) \\
\left(P D E N=D E N_{-} / \Sigma_{N}^{N} D E N . \text { DEN. : pop. density of i district) }\right.\end{array}$ \\
\hline \multirow{2}{*}{ Moran's I } & $\frac{N \sum_{i=1}^{n} \sum_{j=1}^{n} W_{i j}\left(X_{i}-\bar{X}\right)\left(X_{j}-\bar{X}\right)}{\left(\sum_{i=1}^{n} \Sigma_{j=1}^{n} W_{i j}\right) \sum_{i=1}^{n}\left(X_{i}-\bar{X}\right)^{2}}$ \\
\hline & $\begin{array}{c}\text { (N: no. of dongs, } \mathrm{X}_{\mathrm{i}} \text { : pop. of } \mathrm{i} \text { dong, } \mathrm{X}_{\mathrm{j}} \text { : pop. of } \mathrm{j} \text { dong, } \\
\overline{\mathrm{X}} \text { : mean pop., } \mathrm{W}_{\mathrm{i}}: \text { weight of } \mathrm{i} \text { and } \mathrm{j} \text { dongs) }\end{array}$ \\
\hline SDD & Same as equation (4) \\
\hline
\end{tabular}

\subsection{Data and Analysis Target}

This study utilizes micro data at the 2\% level provided by the Micro Data Service System (MDSS) of the 2005 Population and Housing Census Data (Korea National Statistical Office) at the personal level. The selection of samples at the $2 \%$ level is under the root proportional allocation after being layered by layering variables including district area, and type of residence. In the data, people over 18 years old able to drive and to commute to a workplace or school were included. Among them, those who reside in cities and use cars for commuting, thus for whom VHT can be obtained, were eventually selected. Data were extracted with different variables from among 79 cities with a population between 0.1 and 3 million in order to minimize the differences in the cities in terms of urbanization level. Finally, data regarding 95,477 people and 79 cities were employed for this study. This study was based on statistical data found for each city and on 2005 census data provided by local governments as a means to establish data for each variable. To examine the form of each urban city and road system, GIS data (Ministry of Land, Infrastructure and Transport) for each city in 2005 was analyzed using ArcGIS 10.3.

The data for the descriptive statistics of each variable are shown in Table $6 . \& 7$. below.

Table 6. Descriptive Statistics of Each Variable

\begin{tabular}{lc}
\hline \multicolumn{1}{c}{ Variables } & Ratio \\
\hline Gender & Male: $67.5 \%$, Female: $32.5 \%$ \\
Educational & Elementary: $5.4 \%$, Middle school: $6.6 \%$, High school: \\
background & $37.5 \%$, College: $45.3 \%$, Graduate school: $5.2 \%$ \\
Job & Others: $0.8 \%$, Professional: $15.8 \%$, Engineering: \\
& 9.6\%, Office: $17.6 \%$, Service: $7.0 \%$, Sales: $9.5 \%$, \\
& Agriculture: $4.9 \%$, Technical: $9.8 \%$, Machine \\
& operation: $11.3 \%$, Labor: $6.0 \%$ \\
Housing & Free housing: $3.1 \%$, Own: $62.4 \%$, Lump -sum \\
tenure & deposit: $19.8 \%$, Monthly rent: $14.7 \%$ \\
Transportation & Mass transportation: $27.8 \%$, Car: $72.2 \%$ \\
modes & \\
Place of & Inner city: $83.0 \%$, Suburban: $17.0 \%$ \\
residence & \\
\hline
\end{tabular}

Table 7. Descriptive Statistics for Each Variable

\begin{tabular}{lccccc}
\hline \multicolumn{1}{c}{ Variables } & Ave. & SD & Min. & Max. & Median \\
\hline Age & 38.24 & 11.50 & 18 & 75 & 38 \\
Density & 9251.5 & 7746.2 & 1469.9 & 31517 & 6381 \\
Diversity & 0.22 & 0.07 & 0.12 & 0.55 & 0.2 \\
Design & 2.88 & 1.49 & 1 & 10.9 & 2.66 \\
Commercial & 1.65 & 1.22 & 0.16 & 5.72 & 1.4 \\
accessibility & & & & & \\
Apartment & 4.72 & 1.01 & 1.41 & 8.92 & 4.8 \\
accessibility & & & & & \\
Business accessibility & 1.02 & 0.71 & 0 & 2.09 & 0.8 \\
Bus accessibility & 208.32 & 260.23 & 0 & 1535 & 122 \\
Subway accessibility & 0.05 & 0.14 & 0 & 0.95 & 0.1 \\
Gini centrality & 0.57 & 0.13 & 0.28 & 0.87 & 0.51 \\
(Relative) Entropy & 0.75 & 0.12 & 0.45 & 0.97 & 0.74 \\
Moran's I & 0.14 & 0.21 & -0.24 & 0.93 & 0.09 \\
SDD & 6.22 & 2.49 & 1.45 & 12.51 & 6.1 \\
\hline VHT & 7.77 & 4.68 & 1 & 25 & 4 \\
\hline
\end{tabular}

The subjects of this study are urban areas, not rural areas. According to administrative districting in Korea, "Si" refers to more urbanized areas, while "Gun" is applied to more rural areas. In general, areas with

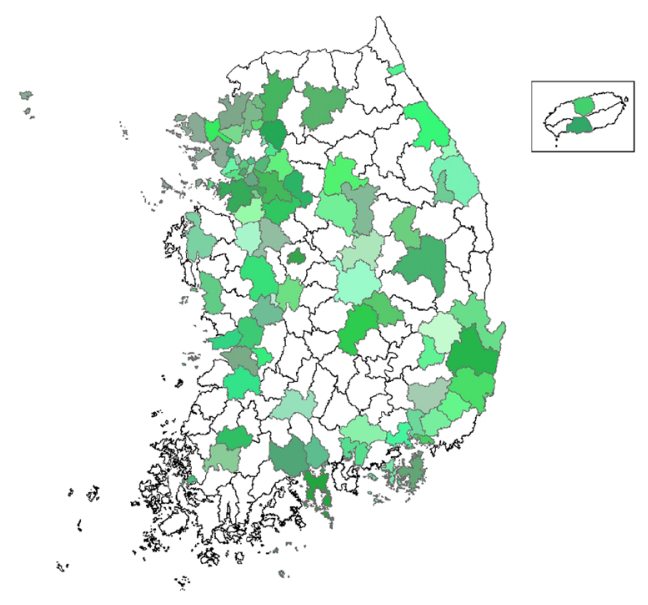

Fig.1. Location of 79 Cities in Korea 
a population of more than 100,000 are assigned the administrative unit of "Si." This study examined such units.

\section{Analysis Results \\ 4.1 Review of Models}

The results of the models in this study are as follows. The primary confirmation on whether the HLM used in this study is significant was performed in advance. This was done to ascertain how VHT differs in each city. Through this confirmation, it can be decided whether to use HLM that handles more than the two levels or the general regression model for the analysis. The model to this end is called the NULL model and, by convention, this study names it Model 1 (Table 8.). The analysis result from Model 1 shows a similar design in cities with the same VHT by individuals and a different model in other cities. It could be judged as the significant level of the constant, which is 0.000 , significant at the $1 \%$ level. It may be verified that HLM as configured in this study is a more proper method than general regression analysis. In addition, it is confirmed that VHT by individuals do in fact differ by city.

Next, models were examined in order to ascertain which one holds the greatest explanatory power so that actual analysis can be performed with only that model. The analysis result of whether the amount of deviance variation is significant at the 95\% level, using degree of freedom and $\chi^{2}$ distribution of each model, are described in Table 8 . As a result, it can be seen that Model 2 rather than Model 1, Model 3 rather than Model 2, and Model 4 rather than Model 3 is superior. In other words, it was verified that Model 4 is the best model. In Section 4.3, real analysis was carried out using Model 4.

\subsection{Variance Review}

As mentioned previously, the $\mu k$ of equation $(\mathrm{k})$ is a tool that can verify whether the degree of relation of individual variables and VHT depends on cities. In other words, we can conclude that if $\mu k j$ is significant, the level of effect that a relevant individual variable has on VHT varies from city to city. As illustrated in Table 8., from $\mu 1$ to $\mu 20$, all variances of twenty-one individual variables excluding age and educational background were significant. This means that the degree of effect of these seventeen individual variables on VHT varies by city, proving hypothesis 5 .

\subsection{Analysis of Results}

The analysis of results focusing on Model 4, which was identified as the most excellent model as a result of model analysis in Section 4.1, is as follows.

Most of the individual-level variables showed meaningful results. As for place of residence, living in a suburban area increased VHT, which is an understandable result. As for gender, females demonstrated shorter VHT. Meanwhile, as the age of subjects rise, VHT increased. As for transportation modes, using a vehicle reduced VHT. This is because Korean cities still maintain a car-oriented structure. As for educational background, college and graduate school graduates showed remarkably high VHT. As for housing tenure, lump-sum deposit and monthly rentbased residents did not demonstrate any difference in VHT compared to those living in the home of free housing residents, while homeowners showed noticeably high VHT. All job categories showed longer VHT compared to the 'other jobs' category. The VHT of workers in service and sales fields were not much longer than those in the other job group, while those of professionals, engineers, and office workers were longer. In summary, those with higher socioeconomic status such as highly-educated individuals, professionals, office workers, and homeowners, demonstrated longer VHT.

The results for variables at the urban level are as follows. First, density, diversity, and design were examined. As for density, higher density meant longer VHT, but the degree is not particularly significant. As for diversity, greater diversity resulted in shorter VHT, with a quite high level at -2.300 , indicating that diversity is one of the decisive factors for lowering VHT. It turns out that design also increases VHT, but at a low degree of 0.019 and thus is not relevant.

Next, distance to transit and destination accessibility were examined. First, destination accessibility has a significant relation to VHT. Especially for commercial and business facilities, shorter distances to transit mean shorter VHT (-0.101 \& -4.257). Distance to transit also has a significant relationship with VHT by reducing them. It turns out that high accessibility to bus stops rather than to subway stations leads to lower VHT.

Lastly, all urban form factors show a significant relation to VHT. As mentioned in the definition of the variables, compact cities generally have high Gini Centrality, Entropy, and Moran's I, but low SDD. The results of this study indicate this as well. Higher Gini Centrality, Entropy, and Moran's I mean lower VHT, while higher SDD leads to increased VHT. This result verifies that compact cities do indeed feature fewer VHT.

\subsection{Verification of Hypotheses}

The verification of the hypotheses established in Section 2.3, based on the above analysis results, is as follows.

First, VHT varies depending on cities. This was confirmed by the fact that the constant number of Model 1 was significant.

Second, individual-level variables have an impact on VHT. That the individual level variables of Model 2, 3, and 4 were all significant proves this.

Third, urban form factors produce a decrease in VHT. This was proved by the fact that the urban form variables of Model 4 were all significant.

Fourth, the 5Ds all show a relation with VHT. However, the effect of density and design are not 
Table 8. Analysis Results of Each Model

\begin{tabular}{|c|c|c|c|c|c|c|c|c|c|}
\hline \multicolumn{2}{|c|}{ Variables (Random effect) } & \multirow[t]{2}{*}{ Variance } & \multirow{2}{*}{$\begin{array}{l}\text { Model } 1 \\
\text { Coeff. }\end{array}$} & \multicolumn{2}{|c|}{ Model 2} & \multicolumn{2}{|c|}{ Model 3} & \multicolumn{2}{|c|}{ Model 4} \\
\hline & & & & Coeff. & s.e. & Coeff. & s.e. & Coeff. & s.e. \\
\hline \multirow{23}{*}{$\begin{array}{l}\text { Individual Level } \\
\text { Characteristics }\end{array}$} & Place of residence $(u l)$ & $0.555^{* *}$ & & $0.826^{* *}$ & 0.105 & $0.855^{* *}$ & 0.106 & $0.857^{* *}$ & 0.107 \\
\hline & Gender $(u 2)$ & $0.322^{* *}$ & & $-0.941^{* *}$ & 0.074 & $-0.945^{* *}$ & 0.078 & $-0.944^{* *}$ & 0.077 \\
\hline & Age $(u 3)$ & 0.001 & & $0.006^{* *}$ & 0.002 & $0.006^{* *}$ & 0.002 & $0.007^{* *}$ & 0.027 \\
\hline & Transportation modes $(u 4)$ & $1.477^{* *}$ & & $-1.966^{* *}$ & 0.147 & $-2.007^{* *}$ & 0.151 & $-2.011^{* *}$ & 0.153 \\
\hline & Educational background & & & & & & & & \\
\hline & Middle school (u5) & 0.106 & & -0.035 & 0.086 & -0.037 & 0.087 & -0.037 & 0.087 \\
\hline & High school (uб) & 0.311 & & 0.045 & 0.100 & 0.046 & 0.101 & 0.046 & 0.101 \\
\hline & College $(u 7)$ & $0.744^{* *}$ & & $0.441^{* *}$ & 0.129 & $0.443^{* *}$ & 0.129 & $0.443^{* *}$ & 0.129 \\
\hline & Graduate school $(u 8)$ & $0.897^{* *}$ & & $0.647^{* *}$ & 0.149 & $0.649^{* *}$ & 0.150 & $0.649^{* *}$ & 0.150 \\
\hline & Housing tenure & & & & & & & & \\
\hline & Home-ownership (u9) & $0.529^{* *}$ & & $0.355^{* *}$ & 0.118 & $0.357^{* *}$ & 0.119 & $0.357^{* *}$ & 0.119 \\
\hline & $\begin{array}{l}\text { Lump-sum deposit-based } \\
(u 10)\end{array}$ & $0.502^{* *}$ & & 0.062 & 0.117 & 0.063 & 0.117 & 0.063 & 0.118 \\
\hline & Monthly rent $(u 11)$ & $0.611^{* * *}$ & & 0.165 & 0.127 & 0.167 & 0.128 & 0.167 & 0.128 \\
\hline & Job & & & & & & & & \\
\hline & Professional (u12) & $1.020^{* *}$ & & $0.962^{* *}$ & 0.198 & $0.997^{* *}$ & 0.199 & $0.999^{* *}$ & 0.201 \\
\hline & Engineering (u13) & $1.076^{+}$ & & $0.878^{* *}$ & 0.212 & $0.880^{* *}$ & 0.214 & $0.881^{* *}$ & 0.218 \\
\hline & Office work (u14) & $1.400^{* *}$ & & $0.961^{* *}$ & 0.210 & $0.969^{* *}$ & 0.215 & $0.972^{* *}$ & 0.218 \\
\hline & Service work $(u 15)$ & $1.368^{* *}$ & & $0.336^{\dagger}$ & 0.201 & $0.341^{\dagger}$ & 0.204 & $0.343^{\dagger}$ & 0.205 \\
\hline & Sales work $(u 16)$ & $1.053^{* *}$ & & $0.378^{\dagger}$ & 0.221 & $0.381^{\dagger}$ & 0.224 & $0.385^{\dagger}$ & 0.225 \\
\hline & Agriculture (u17) & $1.624^{* *}$ & & $1.095^{* *}$ & 0.231 & $1.104^{* *}$ & 0.241 & $1.109^{* *}$ & 0.243 \\
\hline & Technical work $(u 18)$ & $1.267^{* *}$ & & $1.000^{* *}$ & 0.196 & $1.019^{* *}$ & 0.201 & $1.020^{* *}$ & 0.202 \\
\hline & Machine operation ( $u 19)$ & $1.001^{* *}$ & & $0.555^{* *}$ & 0.167 & $0.560^{* *}$ & 0.169 & $0.561^{* *}$ & 0.171 \\
\hline & Labor work $(u 20)$ & $0.413^{* *}$ & & $0.547^{* *}$ & 0.206 & $0.549^{* *}$ & 0.206 & $0.550^{* *}$ & 0.209 \\
\hline \multirow{6}{*}{$\begin{array}{l}\text { 5Ds DESTINATION } \\
\text { ACCESSIBILITY }\end{array}$} & & & & & & -0.001 & 0.007 & 0.002 & 0.012 \\
\hline & & & & & & -1.765 & 1.150 & $-2.300^{* *}$ & 1.047 \\
\hline & & & & & & 0.016 & 0.040 & 0.019 & 0.037 \\
\hline & Commercial accessibility & & & & & -0.017 & 0.042 & $-0.101^{\dagger}$ & 0.062 \\
\hline & Apartment accessibility & & & & & $2.863^{* *}$ & 0.730 & $2.780^{* *}$ & 0.759 \\
\hline & Business accessibility & & & & & $-4.675^{* *}$ & 1.433 & $-4.257^{* *}$ & 1.232 \\
\hline DISTANCE to & Bus accessibility & & & & & $-1.863^{* *}$ & 0.476 & $-2.108^{* *}$ & 0.472 \\
\hline TRANSIT & Subway accessibility & & & & & $-1.138^{\dagger}$ & 0.661 & $-1.232^{\dagger}$ & 0.655 \\
\hline \multirow{4}{*}{ Urban Form } & Gini centrality & & & & & & & $-0.543^{\dagger}$ & 0.407 \\
\hline & (Relative) Entropy & & & & & & & $-1.997^{* *}$ & 0.963 \\
\hline & Moran's I & & & & & & & $-0.496^{\dagger}$ & 0.300 \\
\hline & SDD & & & & & & & $0.001^{\dagger}$ & 0.000 \\
\hline \multicolumn{2}{|l|}{$\overline{\text { Constant/Intercept }\left(u_{0}\right)}$} & $3.222^{* *}$ & $7.063^{* *}$ & $8.106^{* *}$ & 0.416 & $8.149^{* *}$ & 0.371 & $8.164^{* *}$ & 0.375 \\
\hline \multicolumn{2}{|c|}{ d.f.(1) (Individual-level) } & & 95,476 & & 95,456 & & 95,456 & & 95,456 \\
\hline \multicolumn{2}{|c|}{ d.f.(2) (Urban-level) } & & 78 & & 50 & & 42 & & 38 \\
\hline \multicolumn{2}{|l|}{ Deviance } & & 537179 & & 529929 & & 529886 & & 529876 \\
\hline \multicolumn{2}{|l|}{ Change of Deviance } & & - & & 7250.1 & & 42.5 & & 10.8 \\
\hline \multicolumn{2}{|l|}{$\mathrm{P}$ value } & & & & $>41.34$ & & $>15.51$ & & $>9.49$ \\
\hline
\end{tabular}

particularly great. The $3 \mathrm{Ds}$ are effective in terms of reduction of VHT. Especially, diversity, the accessibility of business facilities, and the accessibility of bus stops have a considerable effect on the reduction of VHT.

Fifth, most of the individual-level variables show a relation with VHT, and their impact on VHT varies by city. That the variances of $\mu 1-\mu 20$ shown in Table 8 . are significant confirms this finding. For example, Fig.2. shows that gender has an effect on VHT and Fig.3. indicates that its effect on VHT differs depending on the Entropy of each city. Indeed, the male variable demonstrates higher VHT than does the female. The coefficients in Table 8. were negative numbers. However, this difference is an average result of 79 cities since the difference in VHT as a result of gender could be great or little depending on the Entropy of each city (Fig.3.). This fact can be identified simply by calculating the impact of gender on an individual's VHT below.

Individual's VHT $=7.603+(-1.997) \cdot$ entropy + $\mu 0+(-0.941) \cdot$ gender $+\mu 2 \cdot$ gender $+\gamma \cdots(5)$

( $\mu 0$ : difference in average value by city, $\mu 2$ : difference in influence by city) 
In other words, both higher Entropy and being female lower VHT. However, if $\mu 2$ is significant, it changes the slope of gender by being added to -0.941 . As a result, each city shows different VHT.

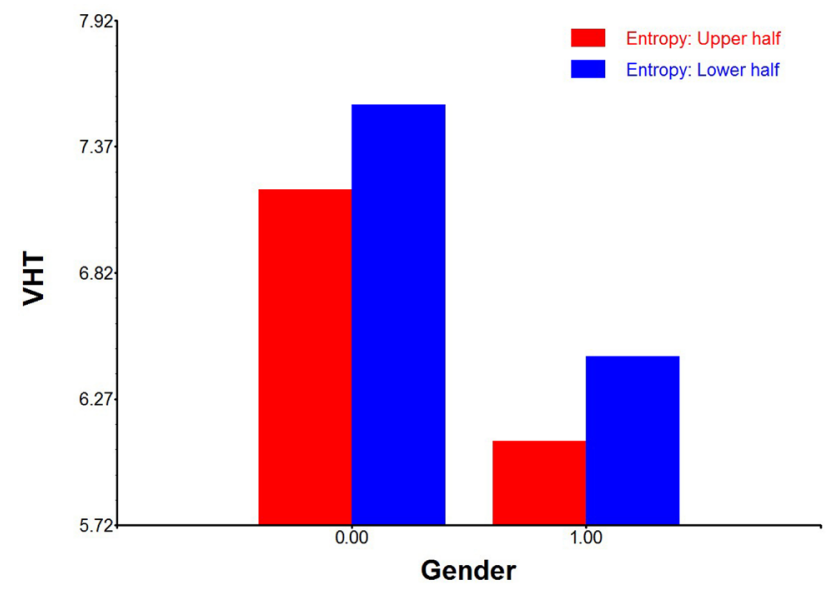

Fig.2. Mean of VHT by Gender and Entropy

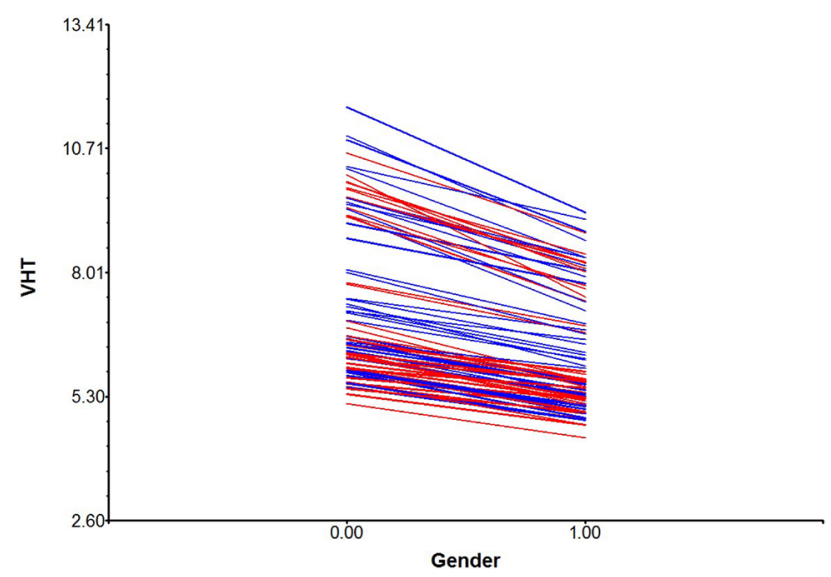

Fig.3. VHT of 79 Cities by Gender and Entropy

However, the final model used in this study only demonstrates the fact that the effect of gender on VHT varies from city to city, not the underlying causes. This is because it did not consider the interaction between individual-level and urban-level variables by not introducing independent variables at the urban level to equation $(\mathrm{K})$. It is hoped that follow-up studies will address this.

\section{Conclusions and Discussion}

As a result of this study, the following implications can be drawn. First, as previously mentioned, density and design show low or no correlation in South Korea, unlike the findings of other existing research. Rather, it is determined here that destination accessibility, accessibility of public transportation, and diversity are the more effective variables. By observing studies from European countries such as the UK, it may be concluded that differences in these two features do not generally affect VHT in South Korean cities that are already equipped with substantial levels of density and diversity. In other words, it can be concluded that securing the diversity of downtown areas, increasing the accessibility of mass transportation, and expanding business and commercial facilities within downtowns can be much more effective for the reduction of VHT in Korean cities.

Second, based on the facts established here, we can determine that the compact city strategy, one of the important related issues, is an effective method for reducing VHT. This is because this study points out that compact city-related elements have a close relation to the reduction of VHT.

Third, more precise and elaborate research on individual-level variables is required for the extension of research related to this study. To achieve this, the effect of individual-level variables, which were treated as dummy variables in this study, on VHT, VMT, and VT should be more thoroughly analyzed. In particular, there is a need for more specific and elaborate research which considers the interaction between individuallevel and urban-level variables left by this study for follow-up research. Detailed research on individuallevel variables should be a first step toward that end, and micro-level research should follow.

As mentioned several times in this study, strategies to reduce VHT should be differentiated according to region. This is because density and diversity, two of the five elements already considered to reduce the car option, are not as effective in Korea compared to findings from research undertaken in the West.

This study analyzed the relation of socio-economic and urban form elements with VHT, focusing on VMT, VT, and VHT which are known to be affected by socio-economic and urban form factors. There have been a range of studies on the relation of the 5Ds and VMT, VT, and VHT. The existence of research by Ewing \& Cervero (2010), who conducted metaanalysis after examining a wide variety of studies, supports this. Against this backdrop, this research, as opposed to the study by Cervero \& Kockelman (1997), approached the question at a broader regional level. It also examined variables representing density, design, and diversity, which are different from the variables used by Cervero \& Kockelman (1997). Therefore, it cannot be concluded that Asian cities, especially Korean cities, differ from Western cities simply based on the result of this study. The differences in variables that could be present in the process of carrying out research on the relation of urban form factors and VHT at the regional level and MAUP (Modifiable Areal Unit Problem) are clear limitations of this study. However, the results of this study are meaningful in that all of the variables applied here were data obtainable at the regional level among the variables used in previous research on VMT, VHT, and VT. It is expected that if follow-up studies with similar subjects (Asian cities) and views were to be carried out, the research results of this study would be valuable as well. 


\section{References}

1) Banister, D. (1992). Energy use, 'transport and settlement patterns' in Sustainable development and urban form. Breheny, M.J.(ed). Sustainable Development and Urban Form. London: Pion Limited, pp.160-181.

2) Bento, A.M., Cropper, M.L., Mobarak, A.M., \& Vinha, K. (2003). The impact of urban structure on travel demand in the United States. (World Bank Policy research working paper \#3007).

3) Bhat, C.R., \& Eluru, N. (2009). A Copula-based approach to accommodate residential self-selection effects in travel behavior modeling. Transportation Research B, 43(7), pp.749-765.

4) Breheny, M. (1996). Centrist, Decentrist and Compromisers. Burton, E., Jenks, M., \& Williams, K.(ed). The Compact City: A Sustainable Urban Form? London: E\&FN Spon.

5) Cervero, R. (2006). Alternative approaches to modeling the travel-demand impacts of smart growth. Journal of the American Planning Association, 72(3), pp.285-295.

6) Cervero, R., \& Kockelman, K. (1997). Travel demand and the 3Ds: Density, Diversity and Design. Transportation Research D, 2(3), pp.199-219.

7) De Bourdeaudhuij, I., Sallis, J.F. \& Saelens, B.E. (2003). Environmental Correlates of Physical Activity in a sample of Belgian Adults. American Journal of Health Promotion, 18(1), pp.83-92.

8) EPA. (2014). Sources of Greenhouse Gas Emissions: Transportation Sector Emissions. Retrieved from http:/www.epa. gov/climatechange/ghgemissions/sources/transportation.html

9) Ewing, R., Bartholomew, K., \& Winkelman, S. et al. (2008). Growing Cooler. Washington, DC: Urban Land Institute.

10) Ewing, R., \& Cervero, R. (2010). Travel and the Built Environment: A Meta-Analysis. Journal of the American Planning Association, 76(3), pp.265-294.

11) Ewing, R., De Anna, M. \& Li, S. (1996). Land use impacts on trip generation rates. Transportation Research Record, 1518, pp.1-7.

12) Ewing, R., Greenwald, M.J., Zhang, M., Walters, J., Thomas, J. (2009). Measuring the impact of urban form and transit access on mixed-use site trip generation rates-Portland pilot study. Washington, DC: U.S. Environmental Protection Agency.

13) Frank, L.D., Kavage, S., Greenwald, M., Chapman. J., \& Bradley, M. (2009). I-PLACE3S health \& climate enhancements and their application in King County. Seattle, WA: King County Health Space.

14) Handy, S.L., Cao, X., \& Mokhtarian, P.L. (2005). Correlation or Causality between the built environment and travel behavior? Transportation Research D, 10(6), 427-444.

15) Hox, J.J. (2010). Multilevel Analysis: Techniques and Applications (2nd Ed.), New York: Routledge.

16) Jeffrey Tumlin (2011), Sustainable transportation planning, Wiley.

17) Masako, M. (2014). Role of Community-Based Approaches with Administrative Support in an Urban Low-Carbon Society in the UK. Journal of Asian Architecture and Building Engineering, 13(3), pp.593-600.

18) Minho, S., Alex, K. \& Seiyong, K. (2013), Environmental and Economic Impacts of Transit-Oriented Corridors in Korea, Journal of Asian Architecture and Building Engineering, 12(2), pp.221228.

19) Newman, P.W.G., \& Kenworthy, J.R. (1989). Gasoline consumption and cities. Journal of the American Planning Association, 55(1), pp.24-37.

20) Rajamani, J., Bhat, C.R., Handy, S., Knaap, G., \& Song, Y. (2003). Assessing the impact of urban form measures in nonwork trip mode choice after controlling for demographic and level-ofservice effects. Transportation Research Record, 1831, pp.158165.

21) Raudenbush, A.W., \& Bryk, A.S. (2002). Hierarchical Linear Models (2nd Ed.), Thousand Oaks: Sage Publications.

22) Seung-Jae L., Kyung-Hoon L. \& Seok-Jin K. (2013), Study on a Pedestrian Simulation Model of Natural Movement, Journal of Asian Architecture and Building Engineering 12(1), pp.41-48.
23) Tsai, Y.H. (2005). Quantifying Urban Form: Compactness versus Sprawl. Urban Studies, 42(1), pp.141-161.

24) Yunnam, J., Gunwon, L., \& Seiyong, K., (2015) Analysis of the Relation of Local Temperature to the Natural Environment, Land Use and Land Coverage of Neighborhoods, Journal of Asian Architecture and Building Engineering 14(1), pp.33-40.

25) Zhao, P. (2011). Managing urban growth in a transforming China: Evidence from Beijing. Land Use Policy, 28(1), pp.96-109.

26) Zhou, B., \& Kockelman, K. (2008). Self-selection in home choice, Transportation Research Record, 2077, pp.54-61. 